\title{
Perceived Over-qualification and Job Satisfaction of New Graduates: A Moderated Mediation Model
}

\author{
Linsheng Xiao ${ }^{1, *}$ Ying Wang ${ }^{2}$ \\ ${ }^{1}$ Business School, Beijing Institute of Technology, Zhuhai, Zhuhai, Guangdong 519088, China \\ ${ }^{2}$ Government and Society College, University of Birmingham, Birmingham B152TT, UK \\ *Corresponding author. Email: lsxiao2010@126.com
}

\begin{abstract}
In this paper, the relative deprivation theory is used as the basis to explore the mechanism and boundary conditions of the effect of over-qualification on the job satisfaction of new graduates. An empirical study based on 341 matching data in two stages found that: (1) Perceived over-qualification negatively affects job satisfaction and positively affects relative deprivation; (2) Relative deprivation played a mediating role in the relationship between over-qualification and job satisfaction; (3) Leadership empowerment behaviour moderated the relationship between relative deprivation and job satisfaction. In the case of low-level leadership authorization, the relative deprivation of new graduates has a stronger impact on job satisfaction; (4) Leadership authorization further moderates the indirect effect of perceived over-qualification on job satisfaction through perceived relative deprivation. In the case of high-level leadership authorization, the indirect effect of perceived over-qualification on job satisfaction is weaker than that of perceived deprivation.
\end{abstract}

Keywords: Perceived over-qualification, Relative deprivation, Leadership authorization, Job satisfaction.

\section{INTRODUCTION}

In 2019, the gross enrolment rate of higher education in China reached $51.6 \%$, and the total number of students in school exceeded 40 million [1]. This means that China's higher education has achieved a rapid transition from elite to popularization and even universalization in a short period of time. But at the same time, eight or nine million college graduates seek jobs every year, leading to a surplus of talent in the labor market. The pressure of difficult employment, coupled with the impact of the international and domestic economic situation in recent years, has forced more and more college graduates to lower their career standards and engage in jobs that are inconsistent with their academic qualifications, skills, and abilities. Researchers refer to this phenomenon of individuals with qualifications, such as education, skills, and experience, that exceed current job requirements as "over-qualification" [2]. Furthermore, the subjective perception that an individual realizes that his academic qualifications, skills, and experience exceed the job requirements is called perceived over- qualification. Studies have pointed out that overqualification will lead to a series of negative consequences, such as depression, anger and other negative emotions, and reduce individual selfefficacy and organizational commitment [4] [5]. It affects employees' work performance [6] [7], and leads to counterproductive behaviour [8] and even dimission behaviour [9].

So far, scholars inside and outside China has made beneficial exploration on perceived overqualification and its consequences. However, the literature review found that the current research on the effect of over-qualification perception still has some aspects to be improved. First of all, the existing studies on the consequences of perceived overqualification mostly focus on the behaviours of employees, such as organizational citizenship behaviour and counterproductive behaviour [10], while there is insufficient research on the overall attitude reaction of employees to work when they perceive over-qualification, such as job satisfaction. The so-called job satisfaction refers to the positive feeling of work generated by individuals based on the evaluation of work characteristics [11], which reflects 
the degree of physical and mental satisfaction obtained by employees from work [12]. As one of the most important attitude variables, job satisfaction has a strong predictive effect on employees' job performance and turnover intention [13]. According to the literature review, the current researches on the antecedent variables of job satisfaction focus on: labor remuneration, promotion opportunities, job recognition, supervisors and colleagues [14]. Few studies have examined the effect of perceived overqualification on job satisfaction. This study believes that exploring the influencing factors of job satisfaction from the perspective of perceived overqualification can not only enrich the research on the antecedent variables of job satisfaction, but also help the organization to improve employee satisfaction more specifically and reduce the negative consequences caused by perceived over-qualification from the perspective of practice.

Secondly, the mechanism of the influence of perceived over-qualification on job satisfaction remains to be further explored. A few existing studies have confirmed the negative impact of overqualification on job satisfaction [15] [16], but have not explored the process of this effect. Studies have shown that over-qualification indirectly affects employees' attitudes and behaviours through cognitive and affective mechanisms [3]. Among them, variables involved in affective pathway include depression, anger [4] [5] and boredom [3], etc., while variables in cognitive pathway include organizational self-esteem [5] [17] and psychological contract [8]. Relative deprivation, as a psychological variable containing both cognitive and emotional components [18], may be a bridge connecting perceived overqualification and job satisfaction. From the perspective of the individual, the sense of relative deprivation is manifested as the individual's subjective perception of his/her unfavorable position relative to the reference object, as well as the resulting negative emotions such as anger and dissatisfaction [20]. As a group of highly educated people, college students have strong knowledge and skills, and also have high expectations for their future career. Therefore, when college graduates enter the organization and find that the gap between their real work and expectations is too large, they are likely to have a strong sense of relative deprivation, which will lead to negative attitude and behaviour reaction. Therefore, this study predicted that relative deprivation played a mediating role in the relationship between perceived over-qualification and job satisfaction.
According to the theory of relative deprivation, the sense of relative deprivation can trigger the negative emotions of individuals and affect the mental health of employees [21]. However, the degree to which relative deprivation affects employees' emotions and psychology depends on the situation. For example, studies have found that when individuals have a high sense of identity with their group, the negative impact of relative deprivation on mental health is relatively weak [22]. As for the object of this study, compared with traditional employees, the new generation of college students mostly grew up in a superior family environment, have a strong sense of self, like independence and autonomy, and attach more importance to development opportunities and career growth [23]. Due to these characteristics of new graduates, as well as their high human capital stock, this study suggests that if new graduates are trusted and empowered by their leaders at work, the negative effect of relative deprivation on job satisfaction may be weakened. Leadership authorization is actually a set of management behaviours that grant decision-making rights [24]. It means that organizational leaders not only convey to employees that they are valued and respected in the work environment, but also provide work autonomy and guide subordinates to solve difficulties in work. Studies have found that authorization usually helps to improve employees' work attitudes, such as organizational commitment and job satisfaction [25].

To sum up, this research plan takes the specific group of new graduates as the research object. From the perspective of relative deprivation theory, relative deprivation was used as a mediating variable to explore the mechanism of perceived overqualification affecting job satisfaction. At the same time, leadership empowerment was used as a moderating variable to reveal the effect of relative deprivation on job satisfaction. Furthermore, a moderated mediating effect model was constructed to examine the moderating effect of leadership authorization on the mechanism of over-qualification affecting job satisfaction.

\section{THEORETICAL BASIS AND RESEARCH HYPOTHESIS}

\subsection{Perceived Over-qualification and Job Satisfaction}

According to the relative deprivation theory, the difference between what individuals actually get and what they expect and should get affects their 
perception and cognition of things [26]. For new college students, under the influence of the national family planning and education expansion policy, they have received more family attention and education investment, which makes the new generation of employees generally have higher education level, knowledge and ability. However, employees with advanced education, skills or work experience tend to expect the corresponding benefits and returns [27]. When such expectations are not met, they will lose their enthusiasm for work and become bored with work [10]. In essence, perceived over-qualification reflects the mismatch between employees' knowledge, skills and abilities and job requirements, which will lead to a series of negative effects, such as low organizational commitment [28], low happiness [29], high turnover intention and counterproductive work behaviour [30]. To sum up, the following hypotheses are proposed:

H1: perceived over-qualification of new employees negatively affects job satisfaction.

\subsection{The Mediating Role of Relative Deprivation}

As people pay more and more attention to the employment environment and workplace fairness, people pay more and more attention to whether they are deprived in the workplace. According to the theory of relative deprivation, an individual's sense of relative deprivation can not only come from the comparison between the individual and other individuals, or the comparison between the individual's current state and the past or future state, but also from the comparison between the individual's value expectation and value ability [10]. According to Gurr [31], value refers to the events, objects and conditions that people expect. Value expectations refer to the general value status that people think they should attain, while value competence is the general value position that people think they can acquire or keep. Generally speaking, employees who have received higher education have stronger knowledge, skills and abilities (value ability), and correspondingly have higher value expectations in employment, including the desire to gain autonomy in work [32]. As a result, when the new generation of college students are in a position where they feel they are overqualified, they feel the job is "below them". Considering their education level, knowledge and skills, they will think that the job is not worth doing for them. Therefore, when there is cognitive dissonance between what a person is engaged in and what he thinks he should be engaged in, that is, when there is cognitive conflict between value expectation and value ability, the feeling of relative scarcity will be generated [33]. Accordingly, it is proposed:

H2 Perceived over-qualification is positively correlated with perception of relative deprivation.

The core psychological process of relative deprivation is social comparison. Equity theory and relative deprivation theory emphasize that the sense of unfairness and exploitation formed by comparison with reference objects will lead to individuals' negative cognition and emotions [26] [34]. According to Walker [35], when individuals find themselves in a inferior position after comparing their own situation or treatment with reference objects, they will feel exploited and thus produce emotional reactions such as anger and dissatisfaction [22]. Therefore, it can be predicted that when the new generation of college students find an obvious gap between their actual working state and their expected working state, they will think that they have been unfairly treated, which will not only make a negative evaluation of their own work [3], but also may produce dissatisfaction towards the whole organization [25]. This leads to deviant behaviour and avoidance behaviour. Based on the above analysis, the following hypothesis is proposed:

H3: Relative deprivation plays a mediating role between perceived over-qualification and job satisfaction.

\subsection{The Moderating Effect of Leadership Authorization}

Boren [36] believes that authorization behaviour refers to the behaviour that leaders adopt various methods to improve the ability and potential of subordinates on the basis of superior's trust in subordinates, such as letting subordinates make decisions within their responsibilities and encouraging subordinates to participate in decisionmaking. Although relative deprivation has a negative effect on job satisfaction, leadership authorization may weaken the negative effect of over-qualification on relative deprivation. According to the relative deprivation theory, employees who perceive being deprived may wish to escape from the current position by staying in the organization for a short time and voluntarily leaving the organization [37]. However, if the organization empowers them and makes them know that they are valued and trusted by the organization, then the relative sense of deprivation that results from job dissatisfaction is 
likely to be reduced. This is because leadership empowerment gives employees greater autonomy in their work and provides opportunities for subordinates to display their talents. This means that leadership authorization not only gives subordinates the opportunity to experience the sense of meaning of work and obtain self-satisfaction from work, but also improves their psychological security and reduces their perception of uncertainty in the future due to skill enhancement and career growth [38]. Therefore, when the leader has a high level of authorization behaviour, subordinates will have a more positive perception of their work attitude and work behaviour [39]. Based on the above discussion, together with the work characteristics and occupational demands of the research object [23], the following hypothesis is proposed:

H4. Relationship between relative deprivation and job satisfaction mediated by leadership empowerment behaviour is as follows: the higher the level of leadership authorization, the weaker the influence of relative deprivation on job satisfaction of new college students.

\subsection{Moderated Mediating Effect}

For individuals who perceive over-qualification and realize that their personal status has been deprived, high-level authorization can meet the development needs and autonomy needs of employees and make them think that they have enough resources to cope with environmental changes, which in turn stimulate employees' motivation and encourage them to stick to work. On the other hand, employees with low-level authorization believe that they do not have enough resources to cope with environmental pressure, which may lead to negative consequences [40]. Integrating the analysis and deduction logic of the mediating effect and moderating effect of this study, the relative deprivation of new college students explains the mediating mechanism of the influence of perceived excess qualification on job satisfaction (H3). Under high-level leadership authorization behaviour, the influence of relative deprivation on job satisfaction is weaker than that of relative deprivation under low leadership authorization (H4). Therefore, this study believes that under high-level leadership authorization, the mediating effect of perceived overqualification on job satisfaction is weaker than that of perceived deprivation.

H5: Leadership authorization moderates the indirect effect of over-qualification perception on job satisfaction through relative deprivation perception.
Specifically, compared with low-level leadership authorization, the indirect effect of over-qualification perception on job satisfaction through relative deprivation perception under high-level leadership authorization is weaker.

\section{RESEARCH METHOD}

\subsection{Survey Subjects and Sample Characteristics}

E-questionnaires were distributed to new graduates in two stages. In the first stage, a total of 480 questionnaires were sent out, of which 435 were effective, and the effective recovery rate was $90.62 \%$. In the first stage, the demographic information of the subjects was collected and the over-qualification was measured. Sample matching was carried out in the second stage of the survey. 428 questionnaires were sent out and 341 were effectively received, with an effective recovery rate of $79.67 \%$. In this stage, data on relative deprivation, job satisfaction and leadership empowerment were collected. Statistics show that women account for 52.8 percent and men 47.2 percent of the valid samples. In terms of educational level, there are 86 students with junior college degree, 251 students with bachelor's degree and 4 students with master's degree, accounting for $25.2 \%, 73.2 \%$ and $1.2 \%$ respectively, indicating that the subjects of the survey are graduates with bachelor's degree. In terms of working years, $21.1 \%$ have worked for less than half a year, $37.5 \%$ have worked for more than half a year and less than 1 year, $27.0 \%$ have worked for $1-2$ years, and $14.4 \%$ have worked for more than 2 years.

\subsection{Measuring Tool}

The scales of the four variables were all divided into very incongruous, non-congruous, uncertain, congruous, and very congruous by 5 -point scale. The scores ranged from 1 to 5 .

\subsubsection{Scale of Perceived Over-qualification}

Over-qualification perception was measured using the 9-item Scale of perceived over-qualification (SPOQ) developed by Maynard et al. [2]. The scale used a 5-point score, and the higher the score, the stronger the over-qualification perception. In this study, the Cronbach's $\alpha$ coefficient of the scale was 0.808 . 


\subsubsection{Scale of Relative Deprivation}

Scale of relative deprivation is mainly derived from the scale of individual relative deprivation created by Tropp and Wright [41], which consists of 3 items. Combined with the scale developed by Olson et al. [42], a reverse question was added. The scale adopts a 5-point score, and the higher the score, the stronger the sense of relative deprivation. Cronbach's $\alpha$ coefficient of the four items is 0.713 .

\subsubsection{Scale of Leadership Authorization}

Scale of leadership authorization comes from the scale made by Pearce and Sims [43], which is simple and easy to understand, with a total of 6 items, which are filled out by the subordinates. The scale adopts a 5-point score, and the higher the score, the stronger the perceived leadership authorization. In this study, Cronbach's $\alpha$ coefficient of leadership authorization was 0.730 .

\subsubsection{Scale of Job Satisfaction}

Job satisfaction was measured using the scale developed by Shu Rui and Liang Jian [44], consisting of three items. In this study, the Cronbach's $\alpha$ coefficient of the scale was 0.900 , indicating good reliability.

\subsubsection{Control Variable}

In order to eliminate the confusion of independent variables, demographic variables that might influence the study results were included in the control variables. The control variables selected in this study included gender, age, working years, educational level and monthly average income.

\section{RESEARCH RESULTS}

\subsection{Common Method Deviation Control}

In order to reduce the influence of common method bias, the investigation process was controlled, including two-stage matching, anonymity and confidentiality commitment. Harman single factor method was used to conduct statistical test for the common method deviation. The results showed that there were 4 factors with eigenvalues greater than 1 , and the explanation rate of variance of the largest factor was $30.253 \%$. At the same time, confirmatory factor analysis results (see "Table 1") showed that the single-factor model was poorly fitted $\left(\chi^{2}=2743.145\right.$, $\mathrm{DF}=209, \quad \mathrm{IFI}=0.419, \quad \mathrm{TLI}=0.355, \quad \mathrm{CFI}=0.416$,
RMSEA $=0.179$ ). These results indicate that there are no serious common methodological biases in the data.

\subsection{Test of Discriminative Validity}

Confirmatory factor analysis (AMOS21.0) was used to test the discriminative validity of four variables: perceived over-qualification, relative deprivation, leadership authorization, and job satisfaction. The results showed that compared with the other four competing models, the assumed fourfactor model had the best data fitting degree $\left(\chi^{2}=432.265, \mathrm{DF}=164, \mathrm{IFI}=0.918, \mathrm{TLI}=0.904\right.$, $\mathrm{CFI}=0.917$, RMSEA $=0.069$ ). Therefore, the data match well with the model, and hypothesis testing can be carried out.

\subsection{Descriptive Statistics of Variables}

"Table 1" respectively reports the mean value, standard deviation and correlation coefficient of the four research variables. The results showed that job satisfaction was negatively correlated with perceived over-qualification and relative deprivation $(\mathrm{r}=-0.234$, $\mathrm{P}<0.01 ; \mathrm{R}=-0.314, \mathrm{P}<0.01$ ), was significantly positively correlated with leadership authorization $(\mathrm{r}=$ 0.222 , $\mathrm{P}<0.01$ ). There was a significant positive correlation between relative deprivation and perceived over-qualification $(\mathrm{r}=0.195, \mathrm{P}<0.01)$, and a significant negative correlation between leadership authorization and perceived over-qualification $(\mathrm{r}=$ 0.143 , P <0.01), while there was no significant correlation between leadership authorization and perceived over-qualification. The above data provided a preliminary basis for the demonstration of research hypothesis. 
Table 1. Correlation Analysis

\begin{tabular}{|c|c|c|c|c|c|c|c|c|c|c|}
\hline variable & $\mathrm{M}$ & SD & 1 & 2 & 3 & 4 & 5 & 6 & 7 & 8 \\
\hline 1 gender & 0.47 & 0.500 & & & & & & & & \\
\hline 2 age & 2.35 & 0.562 & $0.186^{* *}$ & & & & & & & \\
\hline 3 education & 1.76 & 0.455 & $-0.107^{*}$ & $-0.050^{*}$ & & & & & & \\
\hline 4 working years & 2.35 & 0.969 & $0.129^{*}$ & $0.420^{* *}$ & $-0.365^{* *}$ & & & & & \\
\hline 5 Average monthly income & 2.54 & 0.841 & $0.123^{*}$ & $0.183^{* *}$ & 0.081 & $0.213^{* *}$ & & & & \\
\hline 6 perceived over-qualification & 3.020 & 0.716 & 0.053 & -0.039 & $0.149^{* *}$ & $-0.129^{*}$ & $-0.143^{* *}$ & & & \\
\hline 7 Leadership authorization & 3.623 & 0.592 & $0.122^{*}$ & 0.085 & -0.059 & 0.062 & 0.087 & -0.035 & & \\
\hline 8 relative deprivation & 2.587 & 0.681 & -0.040 & 0.048 & -0.037 & -0.030 & -0.058 & $0.195^{* *}$ & $\begin{array}{l}-0.143 \\
* *\end{array}$ & \\
\hline 9 job satisfaction & 3.519 & 0.824 & 0.041 & 0.029 & -0.095 & $0.116^{*}$ & -0.014 & $-0.234^{* *}$ & $0.222^{*}$ & $-0.314^{* *}$ \\
\hline
\end{tabular}

\subsection{Hypothesis Testing}

Hierarchical regression was used to test hypotheses (see "Table 2"). To test the main effect, the control variables were first put into the regression equation and found to have no significant relationship with job satisfaction. The second step of regression analysis found that, firstly, the perceived overqualification was negatively correlated with job satisfaction $(\beta=-0.231, \mathrm{P}<0.001, \mathrm{M} 4)$. Hypothesis 1 passed the test. Secondly, there was a significant positive correlation between perceived overqualification and relative deprivation $(\beta=0.202, \mathrm{P}$ $<0.001$, M2). Hypothesis 2 was supported.

Table 2. Regression test results of mediating and moderating effects

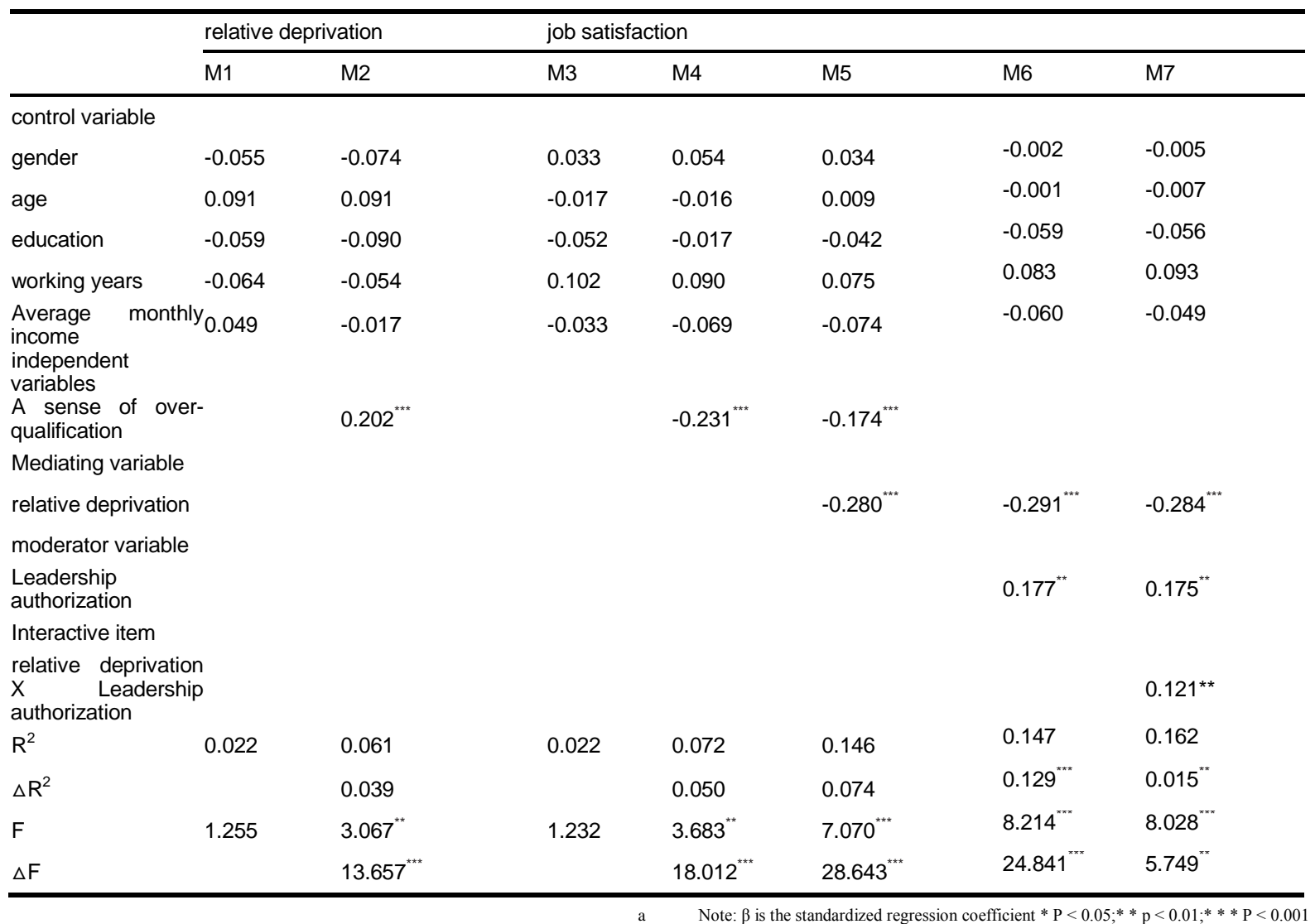


To test the mediating effect, both perceived overqualification and relative deprivation were included in the regression equation. M5 in "Table 3" showed that relative deprivation had a significant negative impact on job satisfaction after adding relative deprivation into the regression equation $(\beta=-0.280$, $\mathrm{P}<0.001$, while the regression coefficient of overqualification on job satisfaction decreased from $0.231(\mathrm{P}<0.001)$ to -0.174 and remained significant $(\mathrm{P}<0.001)$. This result indicates that relative deprivation partially mediates the relationship between perceived over-qualification and job satisfaction, and Hypothesis 3 is supported.

Moderation effect test: In order to eliminate the effect of multicollinearity, relative deprivation and leadership authorization were centralized. On this basis, the interaction item of the two is constructed. M7 showed that the interaction term of relative deprivation and leadership authorization had a significant effect on job satisfaction $(\beta=0.121, \mathrm{P}$ $<0.01$ ), and $\Delta R^{2}=0.015$ ( $\left.P<0.05\right)$, indicating that leadership authorization moderated the relationship between relative deprivation and job satisfaction. Hypothesis 4 was supported. The results of simple slope test showed that the negative relationship between relative deprivation and job satisfaction was stronger under the condition of low-level leadership authorization $\quad(\beta=-0.344, \quad \mathrm{Se}=0.0718, \mathrm{t}=-5.439$, $\mathrm{P}<0.001)$. Under the condition of high leadership authorization, the effect of relative deprivation on job satisfaction was not significant $(\beta=-0.134$, Se $=0.0720, \mathrm{t}=-1.194, \mathrm{P}>0.05)$. Again, hypothesis 4 is supported.

Further, the moderated mediating effect model proposed by Preacher et al. [45] and the Process plugin were used to test the moderated mediating effect. "Table 3" shows that under different levels of leadership authorization, the mediating effect is significantly different. Specifically, in the case of low-level leadership authorization and medium-level leadership authorization, the perceived overqualification has a significant impact on job satisfaction through relative deprivation $(\mathrm{CI}=[-$ 0.1037, -0.0105], excluding 0). However, under highlevel leadership authorization, over-qualification perception has no significant influence on job satisfaction through relative deprivation perception (CI $=[-0.0638,0.0046]$, including 0). This indicates that the higher the level of leadership authorization perceived by new graduates, the weaker the mediating effect of relative deprivation on the relationship between perceived over-qualification and job satisfaction. Hypothesis 5 was tested.

Table 3. Adjustment Path Analysis

\begin{tabular}{|c|c|c|c|c|}
\hline & \multicolumn{4}{|c|}{ Sense of over-qualification -> relative deprivation $->$ job satisfaction } \\
\hline & effect & SE & $95 \%$ con & \\
\hline $\begin{array}{l}\text { Low-level } \\
\text { authorization }\end{array}$ & $\begin{array}{l}\text { leadership } \\
-0.0509\end{array}$ & 0.0241 & -0.1037 & -0.0105 \\
\hline $\begin{array}{l}\text { Medium-level } \\
\text { authorization }\end{array}$ & leadership ${ }_{-0.0431}$ & 0.0202 & -0.0890 & -0.0049 \\
\hline $\begin{array}{l}\text { High-level } \\
\text { authorization }\end{array}$ & leadership ${ }_{-0.0352}$ & 0.0216 & -0.0638 & 0.0023 \\
\hline
\end{tabular}

a Note: Low-level leadership authorization and high-level leadership authorization respectively refer to one standard deviation lower than and higher than the mean value of leadership authorization. Medium-level leadership authorization refers to the mean value of leadership authorization.

\section{RESEARCH SIGNIFICANCE}

\subsection{Theoretical Significance}

First of all, compared with the traditional and classic topic of job satisfaction, over-qualification is a new hotspot in organizational behaviour research in recent years. From the perspective of relative deprivation theory, this study found that perceived over-qualification was an important factor affecting employees' job satisfaction, which enriched the research on the antecedent variables of job satisfaction and provided a new perspective for exploring the work attitude and work behaviour of new college students.
Secondly, the results reveal the mediating role of relative deprivation in the relationship between perceived over-qualification and job satisfaction. Different from previous studies that explored the influence of perceived over-qualification on employees' attitudes and behaviours from cognitive or affective paths, this study, based on the theory of relative deprivation, introduced relative deprivation, a psychological variable that contains both cognitive and affective components. It is confirmed that the influence of over-qualification on job satisfaction is transmitted through relative deprivation, and the process of the effect of over-qualification on job satisfaction is more clearly presented. At the same time, this study also well responded to the call of 
relevant scholars: to deepen the research on the effect of over-qualification on the psychological response [46].

Finally, this study further verified the moderating effect of leadership authorization on the mechanism of over-qualification affecting job satisfaction. It is found that the indirect effect of perceived overqualification on job satisfaction through perceived relative deprivation is not significant under the condition of high leader authorization. So the boundary conditions of the effect of perceived overqualification are defined. At the same time, this paper deeply studies the relationship between relative deprivation and leadership authorization, expands the applicable scope of relative deprivation, and provides empirical support for leadership authorization in the research field of new employees.

\subsection{Practical Significance}

First, in the recruitment process, the concept of talent selection should be changed to establish the concept of "the right is the best". In the recruitment process, the organization shall scientifically and objectively determine the qualifications of personnel based on the requirements of job performance, clarify the recruitment standards, and seek the most suitable talents for the corresponding posts. The selection of talents is the most basic way to avoid the adverse consequences of over-qualification.

Secondly, the effective management of overqualified staff: First, managers should give reasonable authorization and support to new employees. When new employees enter the workplace, they have very limited power. Their direct leaders should delegate some power to new employees according to the matching degree of knowledge, skills and abilities of the employees with the post, so as to satisfy the autonomy of new employees in work and give them the opportunity to display their talents. Secondly, for new employees with excess qualifications, work expansion, job enrichment and job rotation can also be adopted to enrich and increase the work content of new employees, so that those with excess qualifications can assume more responsibilities and carry out a greater degree of self-management.

\section{CONCLUSION}

Based on the matching data of the two-stage survey, the hierarchical regression method and Bootstrap method were used to verify the research model, and the results show that: (1) Perceived over- qualification has a significant negative impact on job satisfaction. (2) Relative deprivation played a partial mediating role in the relationship between overqualification and job satisfaction. (3) Leadership authorization plays a moderating role in the relationship between relative deprivation and job satisfaction. Under high-level leadership authorization, relative deprivation has no significant effect on job satisfaction. (4) Furthermore, leadership authorization moderates the indirect effect of perceived over-qualification on job satisfaction through perceived relative deprivation. The higher the level of leadership authorization, the weaker the mediating effect of relative deprivation on the relationship between over-qualification and job satisfaction.

\section{AUTHORS' CONTRIBUTIONS}

Linsheng Xiao is responsible for research design and contributed to writing, revising and editing, and Ying Wang analysed data and contributed to writing.

\section{REFERENCES}

[1] Ministry of Education, 2019 National Education Development Statistical Bulletin [EB/OL]. (2020-05-20) [2020-11-21]. (in Chinese)

[2] http://www.moe.gov.cn/jyb_sjzl/sjzl_fztjgb/202 005/t20200520_456751.html

[3] Maynard D C, Joseph T A, Maynard A M. Underemployment Job Attitudes, and Turnover Intentions [J]. Journal of Organizational Behaviour, 2006, 27(4): 509-536.

[4] Songqi Liu, Mo Wang. Perceived Overqualification: A Review and Recommendations for Research and Practice [J]. Research in Occupational Stress and Well Being, 2012, 10(1):1-42.

[5] Chen Yingyuan, Zou Zhimin, Pan Junhao. Effects of Over-qualification on Employees' Organizational Citizenship Behaviour: From the Perspective of Emotion [J]. Acta Psychologica Sinica, 2017(1): 72-82. (in Chinese)

[6] Liu S, Luksyte A, Zhou L E, et al. Overqualification and Counterproductive Work Behaviours: Examining a Moderated Mediation Model [J]. Journal of Organizational Behaviour, 2015, 36(2):250-271.

[7] Liu Jinju, Sun Jianmin, Zhang Ruijuan. The Effect of Employee's Perceived Over- 
qualification on Job Performance -The Moderating Roles of Social Exchange [J]. Human Resource Development of China, 2014(15): 33-41. (in Chinese)

[8] Luksyte A, Spizmueller C. When are Overqualified Employees Creative? It Depends on Contextual Factors [J]. Journal of Organizational Behaviour, 2016, 37(5):635-653.

[9] Luksyte A, Spizmueller C, Maynard D C. Why do Overqualified Incumbents Deviate? Examining Multiple Mediators [J]. Journal of Occupational Health Psychology, 2011, 16(3):279-296.

[10] Maynard D C, Parfyonova N M. Perceived Over-qualification and Withdrawal Behaviours: Examining the Roles of Job Attitudes and work values $[\mathrm{J}]$. Journal of Occupational and Organizational Psychology, 2013, 86(3):435455.

[11] Wang Wenxin, Liu Jinju. Over-qualification and Its Effects: A Literature Review [J]. Human Resource Development of China, 2014(13): 3542. (in Chinese)

[12] Randy Hodson. Workplace Behaviours [J].Work and Occupations, 1991, 18(18):271-290.

[13] Hoppock R. Job Satisfaction [M]. New York: Harper and Brothers Publishers, 1935.8-21.

[14] Cui Xun, Zhang Yiming, Qu Jiaojiao. Labor relations atmosphere and employee job satisfaction: the moderating effect of organizational commitment [J]. Nankai Business Review, 2012, 015(002): 19-30. (in Chinese)

[15] Ma Ling, Wang Yu, Xing Yun. The Relationship Between Employee Job Satisfaction, Organizational Commitment and Job Performance [J]. Enterprise Economy, 2013(05): 70-73. (in Chinese)

[16] Eodogan B, Bauer T N. Perceived Overqualification and its Outcomes: The Moderating Role of Empowerment [J]. Journal of Applied Psychology, 2009, 94(2):557-565.

[17] Lobene E V, Meade A W, Pond S B. Perceived Over-qualification: A Multi-Source Investigation of Psychological Predisposition and Contextual Triggers [J]. The Journal of Psychology, 2014, 149(7):1-27.
[18] Cheng Bao, Zhou Xing, Guo Gongxing. Effects of Perceived Over-qualification on Employees' Career Satisfaction: From the Perspective of Cognition [J]. Economic Management, 2019, 41(02):109-123. (in Chinese)

[19] Tougas, F., Beaton. Am. Personal and Group Relative Deprivation: Connecting the "I" to the "We" [M]// Walker I.and Smith HJ. Relative Deprivation: Specification, Development, and Integration, 2002:119-135. Cambridge, UK: Cambridge University Press.

[20] Smith Hj, Pettigrew Tf, Pippin Gm, et al. Relative Deprivation: a Theoretical and Metaanalytic Review [J]. Personality and Social Psychology Review: an Official Journal of the Society for Personality and Social Psychology, 2012, 16(3):203-232.

[21] Xiong Meng, Ye Yiduo. The concept, measurement, influencing factors and effects of relative deprivation $[\mathrm{J}]$. Advances In Psychological Science, 2016, 03:438-453. (in Chinese)

[22] Yuen J Huo, Danny Osborne, Heather J Smith. More than a Feeling: Discrete Emotions Mediate the Relationship between Relative Deprivation and Reactions to Workplace Furloughs $[\mathrm{J}]$. Personality and Social Psychology Bulletin, 2012, 38(5): 628-641.

[23] Schmitt M, Jurgen Maes. Stereotypic Ingroup Bias as Self-defense Against Relative Deprivation: Evidence from a Longitudinal Study of the German Unification Process [J]. European Journal of Social Psychology, 2002, 32(3):309-326

[24] Yang Hongying, Pan Jun. A Study on the Career Growth of the New Generation Employees from the Perspective of the Individual-organization Fit [J]. Contemporary Economic Management, 2016, 038(003): 79-84. (in Chinese)

[25] Zheng Xingshan, Zhen Shanshan, Tang Ningyu. Impacts of Recognition of Stock as Medium on Employees' Job Satisfaction: A Study of Psychological Empowerment as Mediator [J]. Chinese Journal of Management, 2013, 10(1).91-96. (in Chinese)

[26] Xie Wenxin, Yang Chun, Zhou Fan. Overqulification and Employee's Job Crafting: The Impacts of Work Alienation and Psychological Resilience [J]. Science of Science 
and Management of S. \& T., 2015(2):149- 160. (in Chinese)

[27] CROSBY F. Relative Deprivation in Organizational Settings [J]. Research in Organizational Behaviour, 1984, 6(4):51-93.

[28] CABLE, DANIEL M, DERUE, D. SCOTT. The Convergent and Discriminant Validity of Subjective Fit Perceptions [J]. Journal of Applied Psychology, 2002, 87(5):875-884.

[29] FELDMAN B D C. The Antecedents and Consequences of Underemployment among Expatriates [J]. Journal of Organizational Behaviour, 2000, 21(8):889-911.

[30] WU, C.H., LUKSYTE A., and Parker S.K. Over-qualification and Subjective Well-Being at Work: The Moderating Role of Job Autonomy and Culture[J]. Social Indicators Research, 2015, 121(3), 917-937.

[31] Zhao Shenran, Gao Dongdong, Tang Zheng, et al. The Mechanism of Staff Perceived Overqualification Effect on Innovative Behaviour and Job Satisfaction [J]. Psychological Science, 2015(01).433-438. (in Chinese)

[32] GURR, Ted. Why Men Rebel [M].Princeton University Press. 1970.

[33] Vecchio R P, Boatwright K J. Preferences for Idealized Styles of Supervision [J]. Leadership Quarterly, 2002, 13(4):327-342.

[34] ERDOGAN B, TOMAS I, VALLS V, et al. Perceived Over-qualification, Relative Deprivation, and Person-centric Outcomes: The Moderating Role of Career Centrality [J]. Journal of Vocational Behaviour, 2018, 107(8):233 -245.

[35] ADAMS, C. G. The Foraminifera and Stratigraphy of the Melinau Limestone, Sarawak, and its Importance in Tertiary Correlation [J]. Quarterly Journal of the Geological Society, 1965, 121(1-4):283-338.

[36] Walker I, Smith H J. Relative Deprivation Specification, Development, and Integration [M]. Cambridge University Press, 2002.

[37] BOREN R. Don't Delegate-empower. Supervisory Management, 1994, 39(10): 10-18.

[38] Maltarich M A, Reilly G, Nyberg A J. Objective and Subjective Over-qualification: Distinctions, Relationships, and a Place for Each in the
Literature $[\mathrm{J}]$.Industrial and Organizational Psychology, 2011, 4(2):236-239.

[39] HOLLY, H, BROWER, et al. A model of Relational Leadership: The Integration of Trust and Leader-member Exchange [J]. Leadership Quarterly, 2000, 11(2): 227-250.

[40] Seibert, Scott E, Wang, Gang, Courtright, Stephen H. Antecedents and Consequences of Psychological and Team Empowerment in Organizations: A meta-analytic review [J]. Journal of Applied Psychology, 2011, 96(5): 981-1003.

[41] Ding Lin, Geng Zizhen, Bai Shaojun. The Contingent Relationship between Work Stressor and Employee Creativity: The Moderating Role of Psychological Empowerment [J]. Science \& Technology Progress and Policy, 2017(17).148153. (in Chinese)

[42] LR TROPP, SC WRIGHT. Ingroup Identification and Relative Deprivation: an Examination across Multiple Social Comparisons [J]. European Journal of Social Psychology, 1999, 29(5-6):707-724.

[43] James M. Olson, Neal J. Jennifer Meen. The Preconditions and Consequences of Relative Deprivation: Two Field Studies [J].Journal of Applied Social Psychology, 2006, 25(11):944964.

[44] PEARCE, CRAIG L, SIMS, HENRY P. Vertical versus Shared Leadership as Rredictors of the Effectiveness of Change Management Teams: An Examination of Aversive, Directive, Transactional, Transformational, and Empowering Leader Behaviours [J]. Group Dynamics Theory Research and Practice, 2002, 6(2):172-197.

[45] Shu Rui, Liang Jian. Unpacking the Motivational Process of Ethical Leadership: A Self-Concept Perspective [J]. Chinese Journal of Management, 2015, 12(7):10-12. (in Chinese)

[46] Preacher K J, Rucker D D, Hayes A F. Addressing Moderated Mediation Hypotheses: Theory, Methods, and Prescriptions [J]. Multivariate Behavioural Research, 2007, 42(1): 185-227.

[47] Hu. J., B. Erdogan, T.N. Bauer, et al. There are Lots of Big Fish in This Pond: The role of Peer Over-qualification on Task Significance, Perceived Fit, and Performance for 
Overqualified employees [J]. Journal of Applied Psychology, 2015, 100, (4): 12-28.

[48] Zhang Yan. Perceived Over-qualification and Employee Voice Behaviour: A Two-path Model of Cognitive and Emotion [D]. Central China Normal University, 2018. (in Chinese) 